$$
\begin{aligned}
& \text { طراحى و بيادهسازى سيستم كنترل دورزدن خود كار خودرو } \\
& \text { احسان خليلى'، جعفر قيصرى'، محمد دانشَr }
\end{aligned}
$$

' فارغالتحصيل كارشناسى ارشد مهندسى برق، گروه كنترل، دانشكاه صنعتى اصفهان، Ehsan.khalili@ec.iut.ac.ir

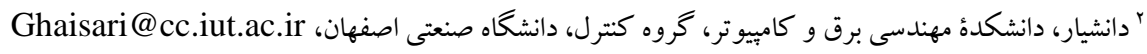

r دانشيار ، دانشكدة مهندسى مكانيك،، گروه سيستمهاى ديناميكى و مكاترونيكى، دانشخاه صنعتى اصفهان، Danesh@ cc.iut.ac.ir

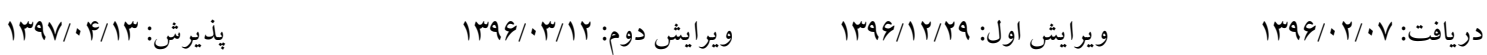

$$
\begin{aligned}
& \text { جكيده: در اين مقاله به طراحى يكك سيستم كنترلى براى دورزدن خود كار خودرو يرداخته مىشود. در ابتدا اطلاعات حاصل از بررسى آيينامهها و } \\
& \text { قوانين راهنمايىوراندگى و نيز تحقيقات انجام شده ازآموزشاهها و يليس راهنمايىوراندگى در اين خصوص جمعبندى و ارائه مى گردد. سبس نتايج } \\
& \text { آزمايشهاى تجربى سيستم دورزدن بر روى خودروى واقعى در خيابانهاى با عرض مختلف ارائه و بررسى مىشود. بِ از آن، مسيرهاى مناسب دورزدن } \\
& \text { خود كار خودرو با در نظر گرفتن محدوديتهاى غيرهولونوميك خودرو طراحى مىشود. در نهايت كنترل كننده مد لغزشى مناسب براى كنترل سيستم دورزدن } \\
& \text { خودرو طراحى مى گردد. طراحى سيستم فازى تصميم گيرى حركت خودرو در هنگام دورزدن نيز نو آورى مهم صورت گرفته در اين مقاله مىباشد. جهت } \\
& \text { تاييد صحت طراحى هاى صورت گرفته با نتايج عملى، يكك ربات شبه خودرو بر اساس ابعاد در مقياس كوجكتر يكك خودروى واقعى طر احى و ساخته شده و }
\end{aligned}
$$

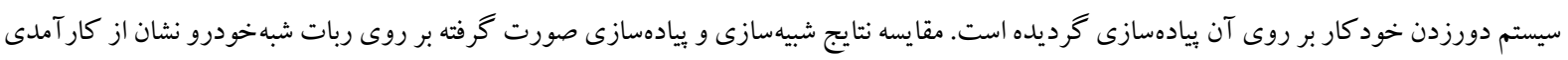

$$
\begin{aligned}
& \text { و دقت مناسب سيستم كنترلى طراحى شده دارد. }
\end{aligned}
$$

$$
\text { كلمات كليدى: سيستمهاى حمل ونقل هوشمند، كنترل كننده مد لغزشى، سيستم دورزدن خودرو، ربات شبهخودرو. }
$$

\title{
Design and implementation of an automatic car turning system
}

\author{
Ehsan Khalili, jafar Ghaisari, Mohammad Danesh
}

Abstract: In this paper, a control system is designed for automatic car turning. At first, the necessary information of car turning that were collected from the traffic bylaw, car driving training centers and traffic police are explained. Then, car turning is studied experimentally on several streets with different widths. Afterward, a proper path is designed for the automatic car turning system considering traffic rules and nonholonomic constraint. Also, an appropriate sliding mode controller is designed and a novel fuzzy decision-making system is proposed for the automatic car turning system. A car like mobile robot is designed and manufactured based on small scale parameters of a sedan car. Finally, the automatic car turning system is implemented on this car like mobile robot. Simulation and experimental results of the designed control system confirm the effectiveness of the proposed control system.

Keywords: intelligent transportation system, sliding mode controller, automatic car turning, car like mobile robot. 
دورزدن در هر مكان و زمان دلخواه توسط راند كان خسارات جانى و مالى

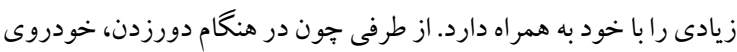

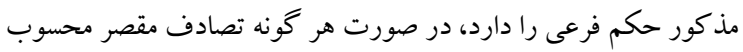

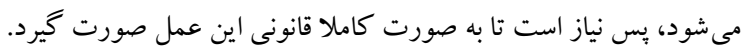

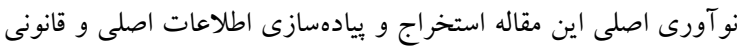

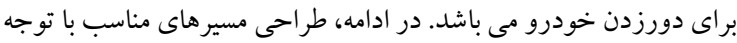

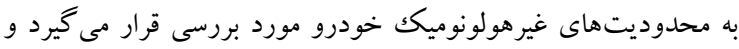

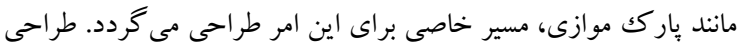

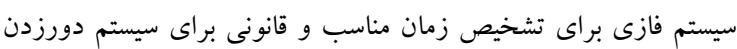

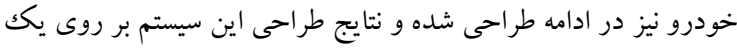

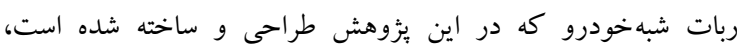
بيادهسازى مى گردد.

\section{r- جمع آورى اطلاعات دورزدن تككفرمان}

\section{خودرو}

در اولين مرجع به آيين نامه راهنمايىوراندكَ برداخته و اطلاعات لازم

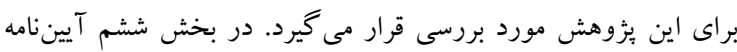

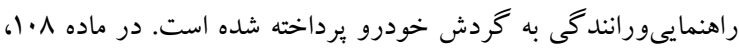

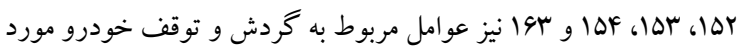

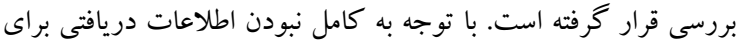

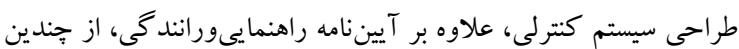
آموزشگاه راهنمايىوراند گى در سطح استان اصفهان استفاده شده است.

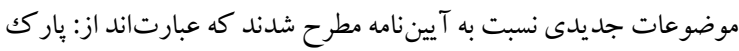
مناسب اوليه كنار خيابان، زمان مناسب و اجازه دورزدن اوليه خودروو،

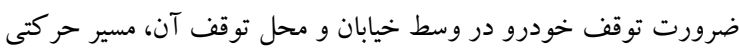

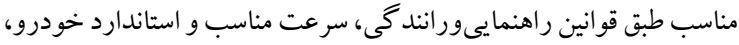
زاويه مناسب خودرو در محل توقف براى ديد مناسب، هوشيارى و

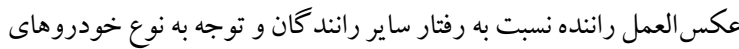

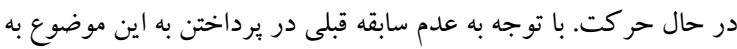

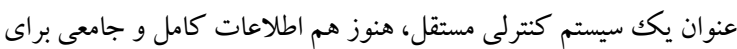

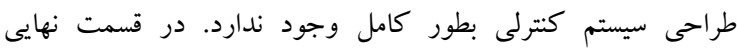

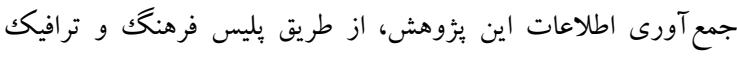

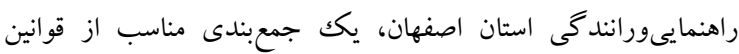

$$
\text { دورزدن خودرو انجام شده است. }
$$

بر اى انجام دورزدن تكك فرمان خودرو، در ابتدا با در نظر گرفتن مادههاى مذكور آيينامه راهنمايىوراندگى مبنى مبنى بر اينكه مكان مورد نظر جز

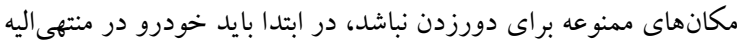

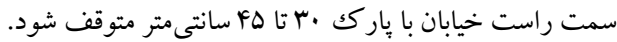

- 1

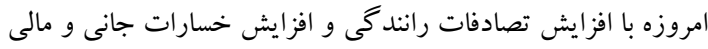
ناشى از اين حوادث، توجه به سيستمهاى حملونقل هوشمند شهرى

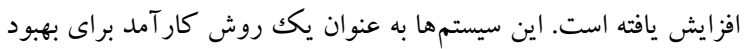

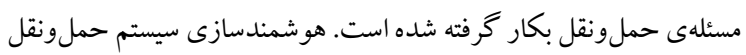

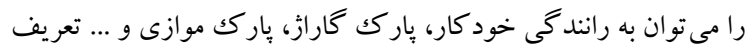
كرد. از آنجا كه حدود •ه درصد تصادفات رانند ركى مربوط به اشتباهات شخص راننده مىباشد، از اين رو محققان به دنبال يافتن راهى جديد در

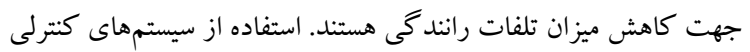

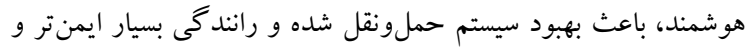

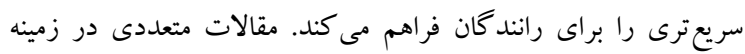

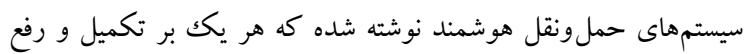

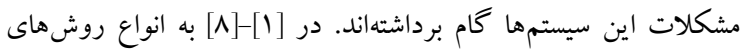

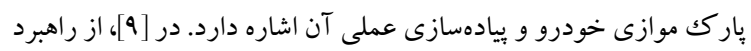
براى جرخش ربات شبهودرو در محيطهاى محصور استفاده SLAM

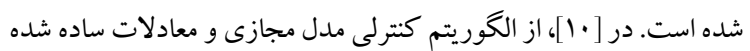

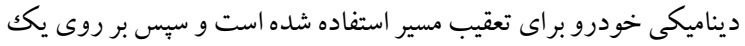

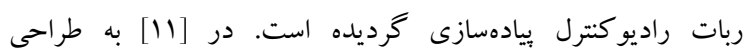

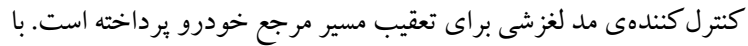

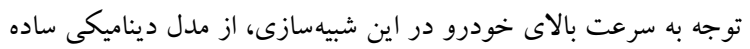

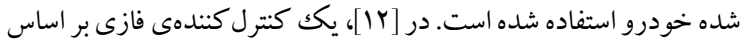

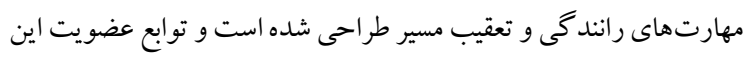

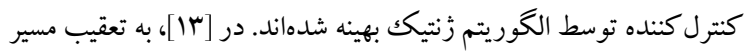
مرجع بر ایى خودرو، هم با مدل ديناميك و هم مدل سينما تيكك مى يردازد و

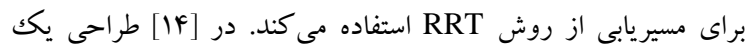

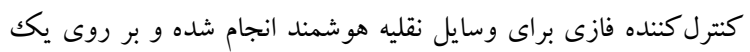
وسيله نقليه شبه خودرو بيادهسازى شده است. در [10] با استفاده از الكوريتم

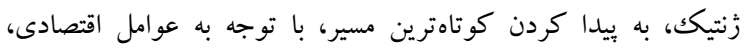

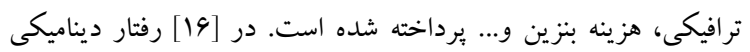

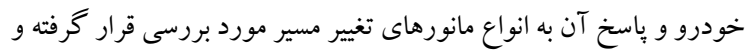

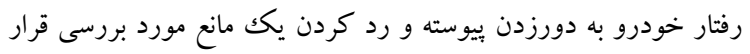

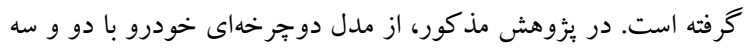
درجه آزادى استفاده شده است. هدف اصلى اين بُزوهش تعميم و افزايش كاربرد سيستمهاى حملونقل

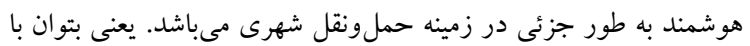

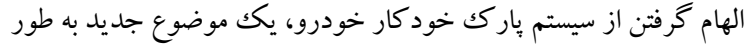

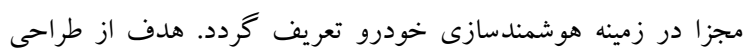
سيستم يار كك موازى خودرو دلايلى جون عدم توانايى راند كان كم تجربه

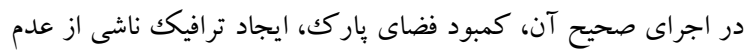

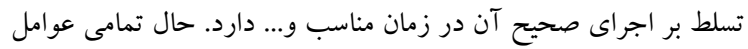
فوق را مى توان براى سيستم دورزدن خود كار خودرو نيز ذكر كرد. انجام 
احسان خليلى، جعفر قيصرى، محمد دانش

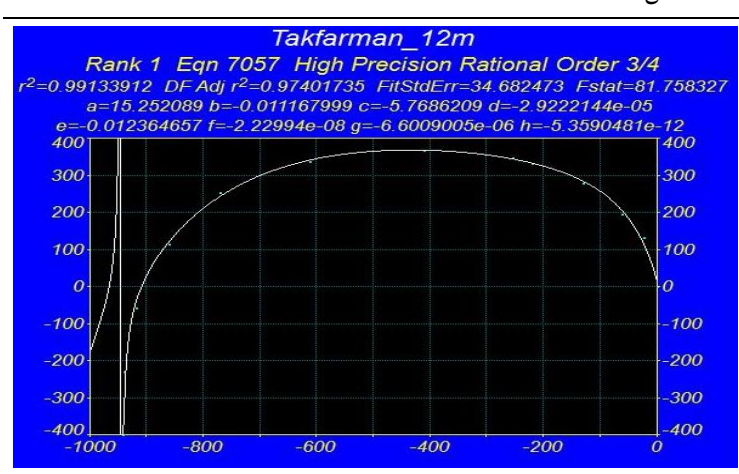

شكل r: برازش اطلاعات مسير خيابان ب ا متر

جدول ا: اطلاعات مسير دورزدن تككفرمان خيابانهاى Y 14، أو 19 متر

\begin{tabular}{|c|c|c|c|c|c|}
\hline$X-12$ & $Y-12$ & $X-14$ & $Y-14$ & $X-16$ & $Y-16$ \\
\hline . & . & . & . & . & . \\
\hline$-Y Y$ & זسו & -10 & סו & $-Y$. & Ir. \\
\hline-4 & $19 \mathrm{~V}$ & $-F Y$ & rMA & $-F V$ & rat \\
\hline$-1 \pi$. & rA. & -11. & rGV & -1.9 & $F \cdot r$ \\
\hline - Yr. & זחז & - YFT & $\Delta . Y$ & $-19 \mathrm{~V}$ & FAD \\
\hline$-r \Delta F$ & rFq & -ral & $\Delta V \Delta$ & $-Y \& q$ & $\Delta V_{1}$ \\
\hline$-F \|$ & ras & -011 & ari & $-r \Delta q$ & 9Tा \\
\hline$-91 Y$ & qMa & -VYG & 91. & $-q q$. & 9V9 \\
\hline$-V V \cdot$ & TOF & $-9 r V$ & $k q$. & $-9 Y$. & $v \cdot 1$ \\
\hline$-\wedge 9$. & 119 & -1.91 & YQ1 & $-\Lambda \cdot \Lambda$ & $v .9$ \\
\hline-918 & $-\Delta V$ & -1111 & Tr & $-9 v \Delta$ & $9 \times 1$ \\
\hline-949 & . & -||$r \mid$ & $-F V$ & $-11 \ldots$ & 914 \\
\hline-941 & $-F .$. & هr|l & $-|r|$ & -IYYY & ו \\
\hline \% & * & $-11 r \Delta$ & $-Y{ }^{\prime}$ & . & HAl \\
\hline * & * & * & * & $-1 T \Delta V$ & YFG \\
\hline 类 & * & * & * & $-\mid M V \Lambda$ & $-\sqrt{4}$ \\
\hline
\end{tabular}

اعداد جدول (1) مختصات (x,y) مسير حركتى خودرو بر حسب سانتى متر در دورزدن تككفرمان خيابانهاى با، F| أو 19 متر مىباشند. حال با استفاده از جدول ا كه بطور عملى بدست آورده شده و از طريق درونيابى با نرمافزار Table Curve 2D به طراحى يكك معادله مسير مناسب براى اين اطلاعات يرداخته شده است (معادلهى (1)). ضرايب اين معادله براى خيابانهاى YIf، If و 19 متر در جدول (Y) نشان داده شده است. در شكل -rا، مسير دورزدن تككفرمان خودرو در خيابانهاى مذكور

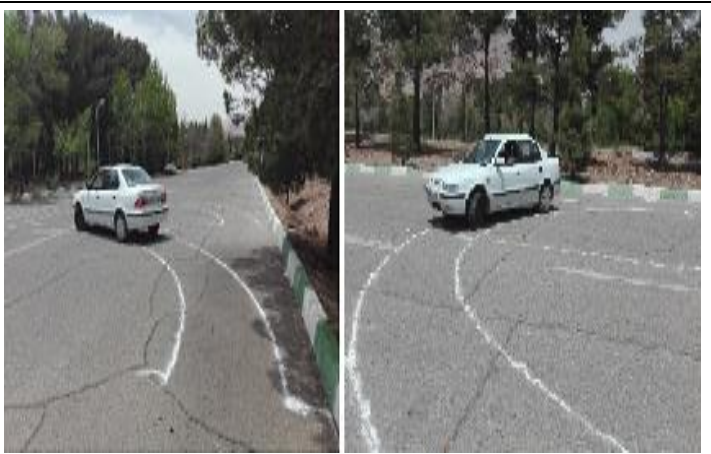

شكل ا: آزمايشات عملى دورزدن تككفرمان با خودروى سمند

سִس مرحله خروج از پِارك اوليه صورت مى گيرد و در اصطلاح با حركت لاككيشتى، خودرو •ه سانتىمتر به جلو حركت كرده تا تقريبا زاويهاى ·ل درجه نسبت به راستاى خيابان به دست آورد. در اين مرحله با توجه به در نظر كرفتن خودروهاى در حال حر كت در باند موافق، به آرامى و با سرعت مناسب اقدام به حركت تا وسط خيابان مى كند. خودرو باطى كردن مسيرى مناسب بر طبق قو انين راهنمايىور انندگى در يشت خط مقطع وسط خيابان متوقف مىشود، بطوريكه سير خودرو بر روى خط مقطع قرار كيرد و از آن عبور نكند. زاويه قرار گيرى خودرو در وسط خيابان بسيار مهم مىباشد جون اين زاويه بايد بكونهاى باشد تا راننده خودرو بيشترين ديد را نسبت به طرف مقابل خيابان و خودروهاى در حال حركت داشته باشد و هم جنين در مرحله بعدى بتواند دورزدن خود را بطور صحيح انجام

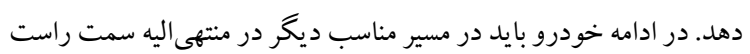
طرف مقابل خيابان حركت خود را ادامه دهد. در ضمن براى انجام دورزدن تككفرمان به عرض حداقل rا متر براى يكك خودروى سوارى معمولى نياز

\section{r- ييادهسازى مسير دورزدن تككفرمان خودرو}

حال با توجه به اطلاعات دريافتى در بخش (Y) لازم است تا اطلاعات فوق بر روى يك خودرو ويادهسازى شود تا بتوان بطور عملى قوانين بدست

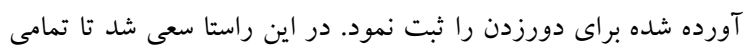
قوانين بيان شده براى دورزدن خودرو بر روى خودروى سمند اجرا و اطلاعات آزمايشات عملى ثبت گرددد. در اين قسمت اجراى صحيح دورزدن خودرو زير نظر كارشناسان مربوطه اجرا شده و با رديابى مسير

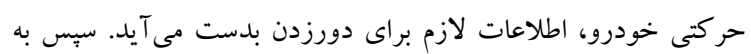
كمكك نرمافزار Table Curve 2D به طر احى يك مسير مناسب براى اين اطلاعات برداخته شد (شكل -Y). اين آزمايشات براى خيابانهاى Y If و 19 متر براى دورزدن تككفرمان خودرو انجام شد كه نتايج آن بصورت

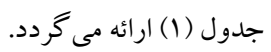


موضوع متفاوت است و تغييرات كوجٍك در طراحى مسير اهميت ندارد و

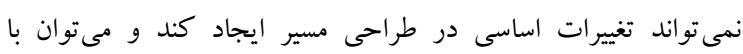
نزديككترين مسير موجود طر احى شده، دورزدن خودرو را انجام داد و يا سيا

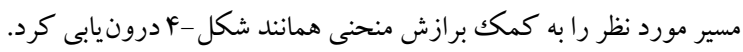

\section{r- طراحى سيستم فازى تصميم}

\section{خودرو}

در اين بخش، موضوع مهم ديخرى مورد بررسى قرار مى گيرد و آن

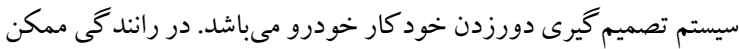

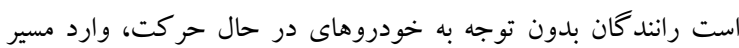
دورزدن خود شوند و خودروهاى در حال حر كت را مجبور به توقف كنند

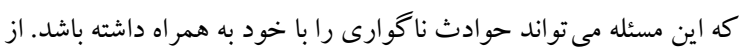

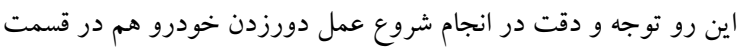
اوليه حر كت و هم در وسط خيابان از اهميت بسيار بالايى برخورد دودار است.

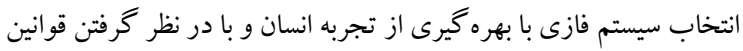

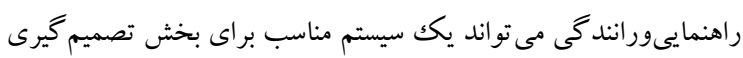

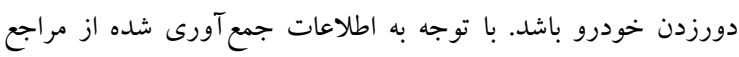
موجود، يكك سرى عوامل اصلى در شروع عمل دورزدن دخيل هستند و

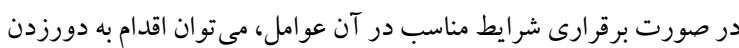
كرد. عوامل مهم در اين قسمت عبارتاند از: فاصله خودروهاى در حرد حال

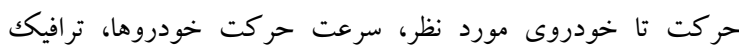

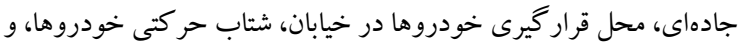

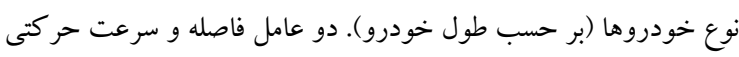

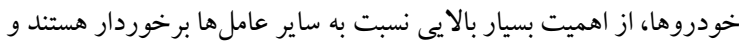

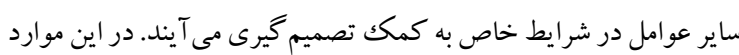

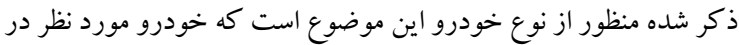
حال حركت جز كدام نوع خودروها مىباشد. خودروى سوارى، ون،

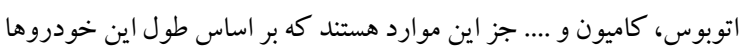
توابع عضويت مشخص شدهاند. يا براى خروجى اين سيستم فازى نيز جهار

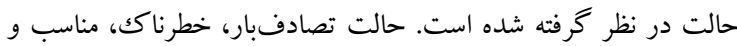
ايمن، جهار تابع عضويت انتخاب شده در اين سيستم فازى مىباشند.

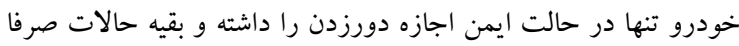
براى اطلاع راننده خودرو از وضعيت خودرو مىباشد. توابع عضويت

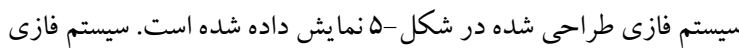
طراحى شده در حالت اوليه شامل VY9 قانون فازى بوده كه بر طبق سترد

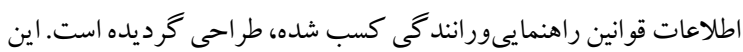
قوانين يس از بررسى دقيق اطلاعات دريافتى از كارشناسان حوزه راهنمايى

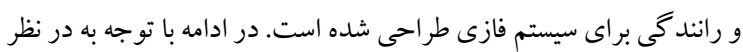

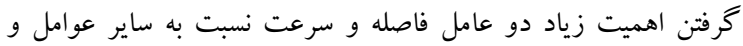

$$
y=\frac{a+c x+e x^{2}+g x^{3}}{1+b x+d x^{2}+f x^{3}+h x^{4}}
$$

جدول r: ضرايب معادله مسير دورزدن تككفرمان در خيابانهاى با، Fأ و

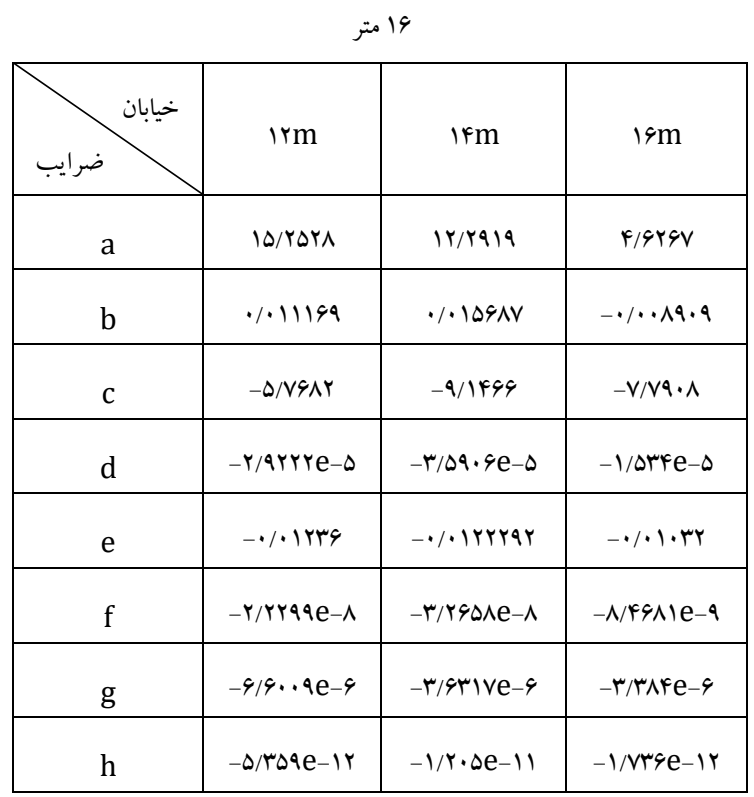

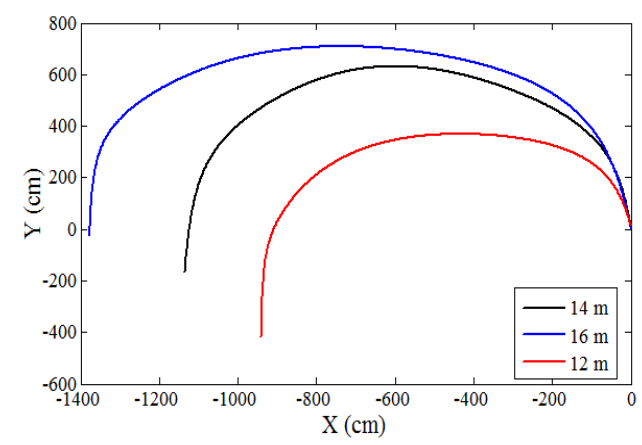

شكل-"ז: دورزدن تككفرمان در خيابانهاى با،

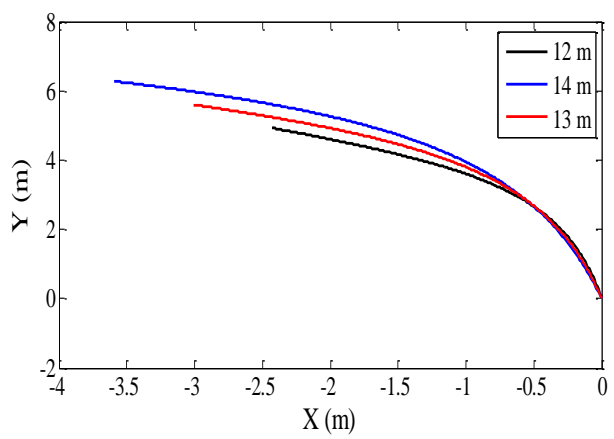

شكل-F) درون يابى مسير رفت دورزدن تككفرمان خيابان سا متر

مسئله دورزدن با بحث بِاركك موازى خودرو از لحاظ طراحى مسير

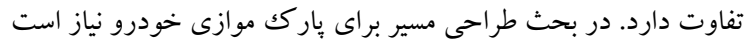

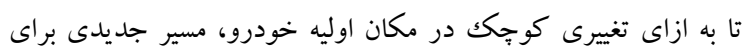
حر كت خودرو طر احى شود زير اكوجِكترين خطا ممكن است سبب ايجاد

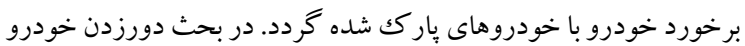


هم حنين حذف يك ورودى فازى با اهميت كمتر، بسيارى از قوانين مشابه حذف گرديده است تا در نهايت به 19 قانون كلى فازى كاهش يأس يابد.

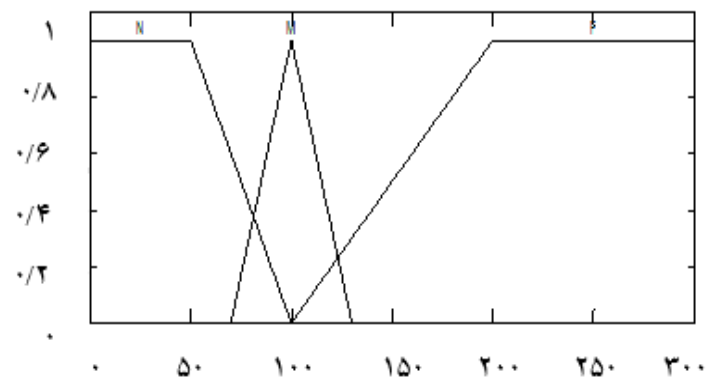

(ب) توابع عضويت فاصله خودروها تا خودرو مورد نظر (m)

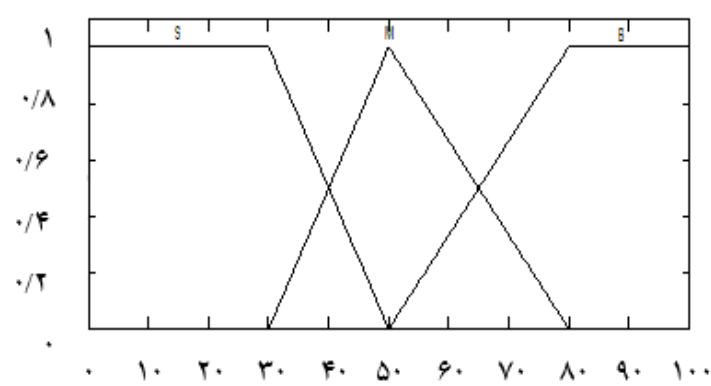

(ت) توابع عضويت سرعت خودروهاى در حال حركت (m/s)

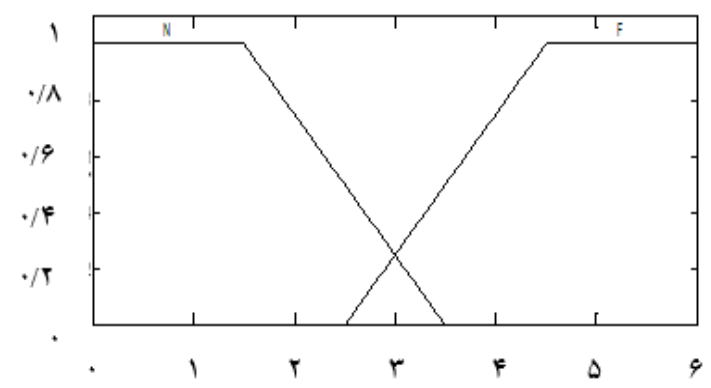

(الف) توابع عضويت محل قرارگيرى خودروها در خيابان (m)

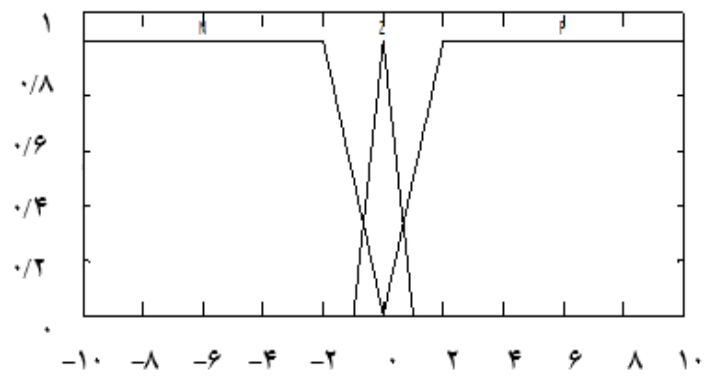

(ب) توابع عضويت شتاب خودروهاى در حال حركت (m/s)
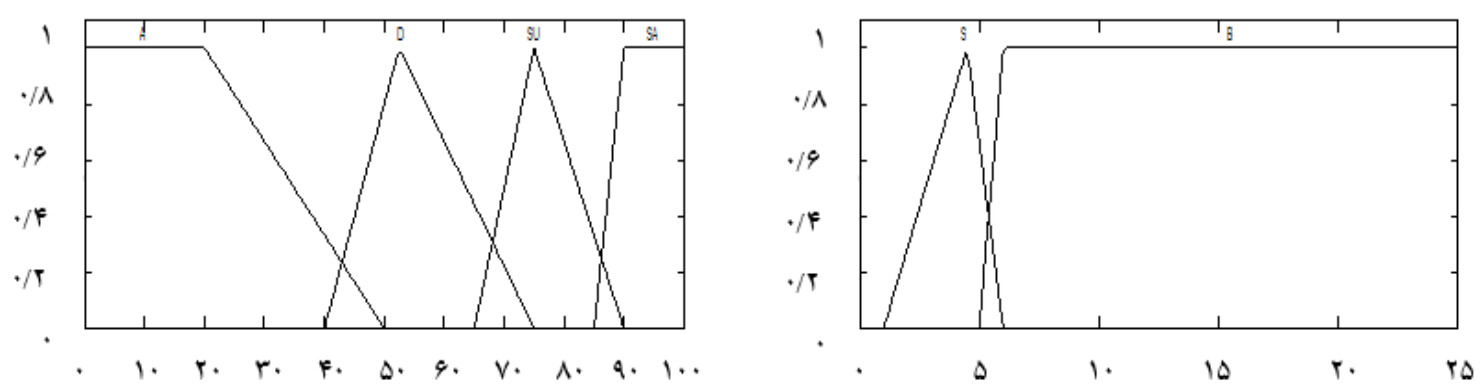

(ج) توابع عضويت خروجى سيسم فازى تصميم گيرى دورزدن

(ث) توابع عضويت نوع خودروهاى در حال حركت (طول خودرو بر حسب متر) شكل-ه: توابع عضويت سيستم فازى تصميم گيرى دورزدن

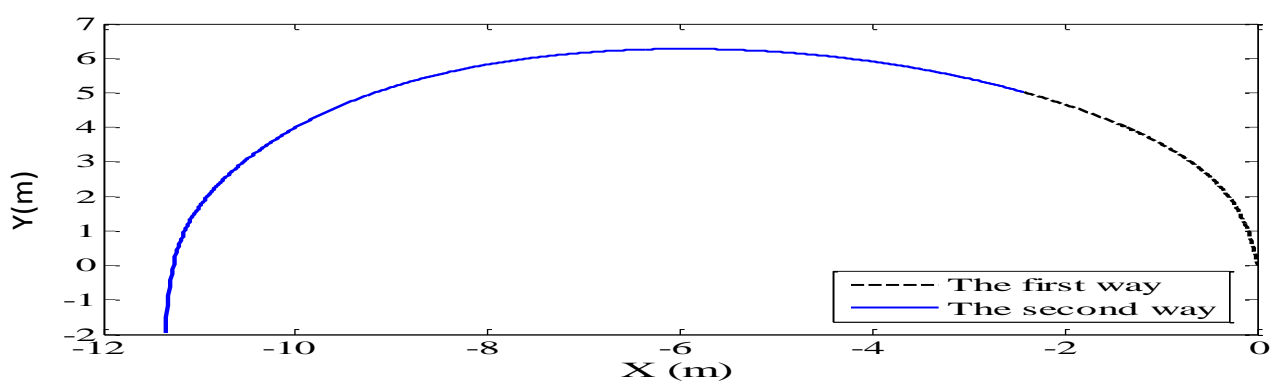

شكل -9: بررسى مسير رفت و بر گشت دورزدن تككفرمان خودرو در خيابان rا متر 
$\mathrm{P}(\mathrm{t})=\left\{\begin{array}{c}\left(\frac{l}{2}-\frac{l}{2} \cos \left(\frac{\pi t}{T}\right)\right)+x_{0} \quad t \in[0 T] \quad \text { if } v<0 \\ -\left(\left(\frac{l}{2}+\frac{l}{2} \cos \left(\frac{\pi t}{T}\right)\right)+x_{0}-l\right) \quad t \in[0 T] \text { if } v>0\end{array}\right.$

همان قوانين زمانى بيان شده در بخش قبل مىباشد. در قوانين زمانى

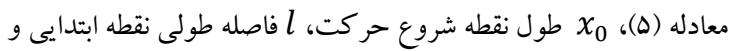

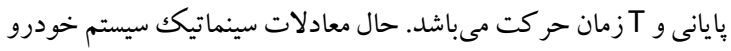

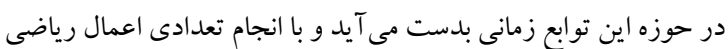

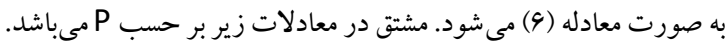

$$
I(\theta, \varphi)\left(\begin{array}{c}
\dot{x} \\
y \\
\dot{\theta} \\
\dot{\varphi}
\end{array}\right)=\left(\begin{array}{l}
v_{1} \\
\omega_{1}
\end{array}\right)
$$

$$
I(\theta, \varphi)=\left(\begin{array}{llll}
\cos \theta \cos ^{2} \varphi & \sin \theta \cos ^{2} \varphi & \frac{l}{2} \sin (2 \varphi) & 0 \\
\sin \theta & -\cos \theta & 0 & 1
\end{array}\right)
$$

در ادامه سطوح لغزش كنترل كننده مد لغزشى مطابق معادله (V) تعريف

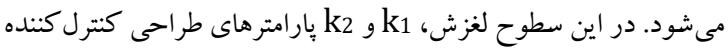

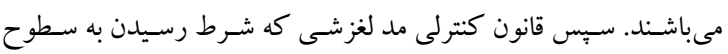

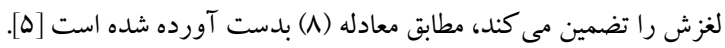

$$
\begin{array}{r}
S=\left(\begin{array}{l}
s_{1} \\
s_{2}
\end{array}\right)=I(\theta, \varphi)\left(\begin{array}{c}
\dot{x}_{e}+k_{1} x_{e} \\
\dot{y}_{e}+k_{2} y_{e} \\
0 \\
0
\end{array}\right)=I(\theta, \varphi)\left(\begin{array}{c}
s_{x} \\
s_{y} \\
0 \\
0
\end{array}\right) \\
\left(\begin{array}{c}
\dot{v}_{1} \\
\omega_{1}
\end{array}\right)=-R|S|^{Q} \operatorname{sign}(S)+I(\theta, \varphi)\left(\begin{array}{c}
\dot{x}_{r}-k_{1} x_{e} \\
y_{r}-k_{2} y_{e} \\
\dot{\theta} \\
\dot{\varphi} \\
\dot{y}^{\prime \prime}
\end{array}\right) \\
+I(\theta, \varphi)\left(\begin{array}{c}
x_{r}-k_{1} \dot{x}_{e} \\
y^{\prime \prime}-k_{2} \dot{y}_{e} \\
\theta^{\prime \prime} \\
\varphi^{\prime \prime}
\end{array}\right)
\end{array}
$$

\section{7- طراحى و ساخت ربات شبه خودرو}

براى بيادهسـازى سـ يستم كنترلى طر احى شـــه در بخش (ه)، نياز به

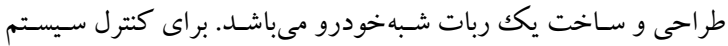

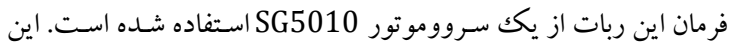

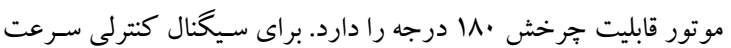

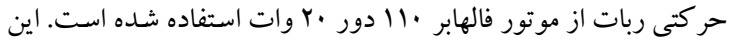

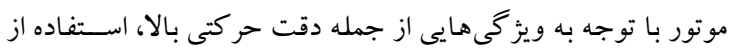
كيربكس خورشـيدى و ... بسيار مورد توجه در حوزه رباتيكك مى بـاشـد.

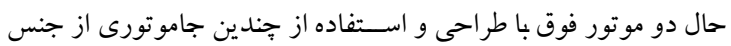

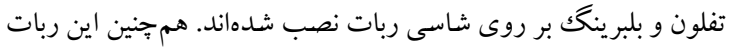

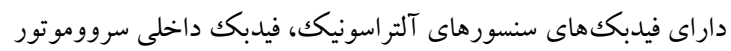

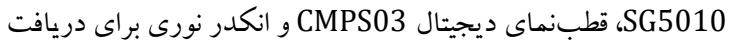

\section{ع- طراحى مسيرهاى رفت و بر تشت دورزدن \\ تكى فرمان}

با توجه به لزوم توقف خودرو در وسط خيابان، مسير حر كتى طراحى

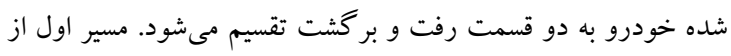

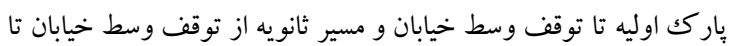

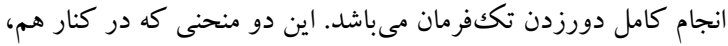

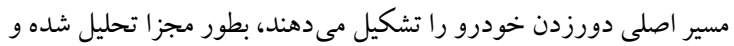

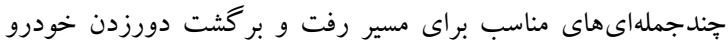

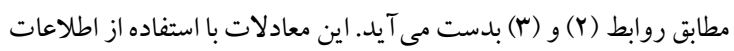

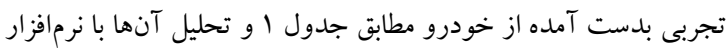

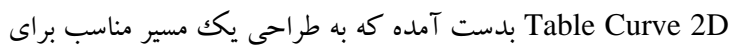

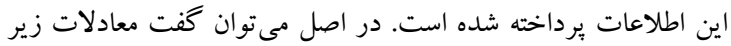

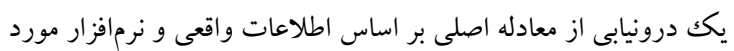

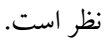

$$
y=\frac{a+c x}{1+b x+d x^{2}}
$$
$\mathrm{a}=\cdot / 1 \cdot \mu r, \mathrm{~b}=-1 / 999, \mathrm{c}=-\mathrm{V} / \mathrm{|V|}, \mathrm{d}=-\cdot / 1 \mathrm{q} 9$ $y=\frac{a+c x+e x^{2}+g x^{3}}{1+b x+d x^{2}+f x^{3}} \quad \mathrm{a}=\cdot / \Delta 94, \mathrm{~b}=-\cdot / \& \Delta \mathrm{F}$ $c=-r / q v r, d=|r|, e=\cdot / W F, f=-\cdot / \cdot v, g=\cdot r r$

\section{0- كنترل كننده مد لغزشى}

براى ييادهسازى سيستم دورزدن تككفرمان خودرو از كنترل كننده مد لغزشـى اسـتفاده مى شــود. اين كنترل كنتده در بر ابر نامعينى و عوامل

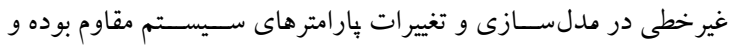

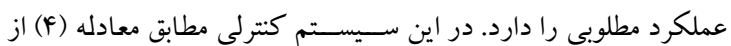

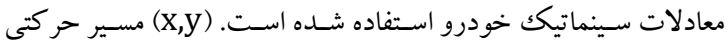

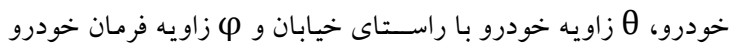

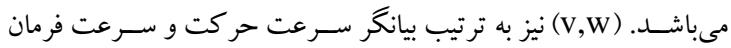

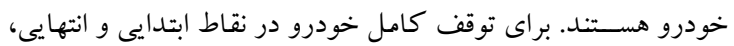

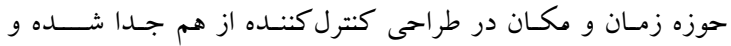

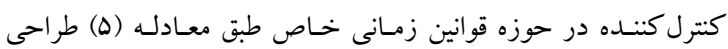
مىشود.

$$
\left[\begin{array}{c}
\dot{x} \\
\dot{y} \\
\dot{\theta} \\
\dot{\varphi}
\end{array}\right]=\left[\begin{array}{c}
\cos \theta \\
\sin \theta \\
\frac{\tan \varphi}{1} \\
0
\end{array}\right] \mathrm{v}+\left[\begin{array}{l}
0 \\
0 \\
0 \\
1
\end{array}\right] \mathrm{w}
$$


ra

طر احى و ييادهسازى سيستم كنترل دورزدن خود كار خودرو

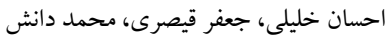
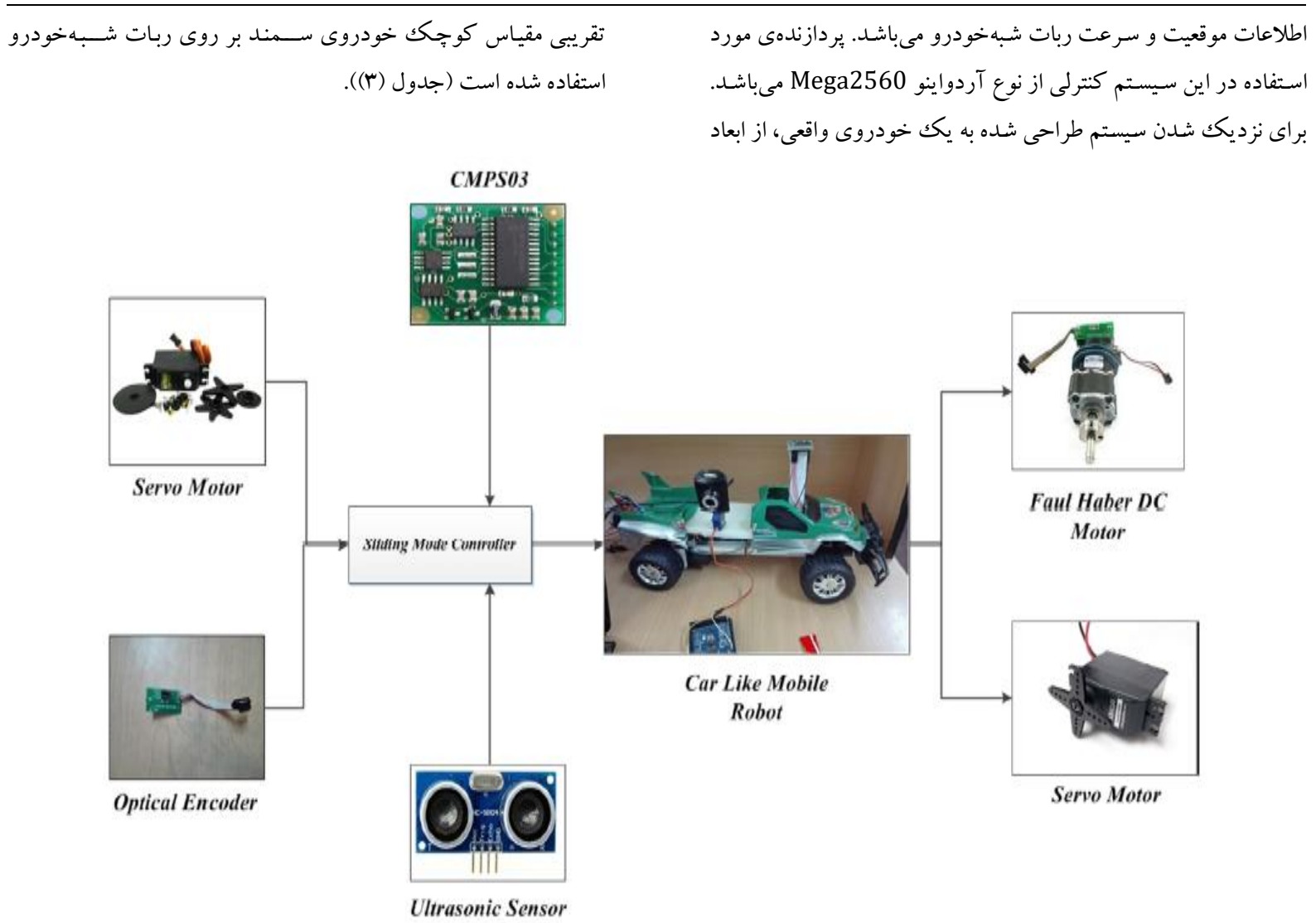

شكل -V: قطعات بكار برده شده در ساخت ربات شبهخودرو

شـبيهسـازى و ييادهسـازى حر كت ربات شـبه خودرو بر روى مسـير

مرجع و واقعى دورزدن تكك فرمان خودرو به ترتيب در شـكل -1 (الف) و (ب) نشان داده شده است. همانطور كه مشخص است ربات مورد نظر توانسـته اســت تا با دقت مناســبى مســير مرجع را تعقيب نمايد. خطاى حركتى ربات در راسـتاى محور X و ل به ترتيب در شــكل-1 (ب) و (ت) نشـان داده شـده اسـت. زاويه هدايت فرمان ربات شبه خودرو نيز در

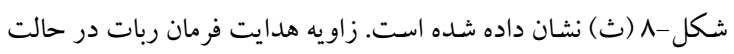
ييادهســازى در بيشــترين مقدار خود قرار دارد كه با توجه به خاصــيت

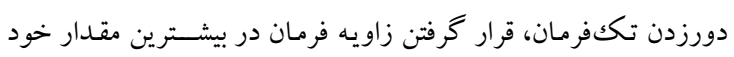
طبيعى است. سرعت مرجع و واقعى دورزدن تككفرمان ربات شبهخودرو 1(ج) نشـان داده شـده اسـت. صـفر شـدن سـرعت ربات در نقاط ابتدايى و انتهايى هم در حالت شبيهسازى و هم بيادهسازى نشان از صحت قوانين زمانى مناسـب در طراحى كنترل كننده دارد. سـطوح لغزش كنترل كننده مد لغزشى نيز در شكل-1^ (ج) و (ح) نشان داده شده است.

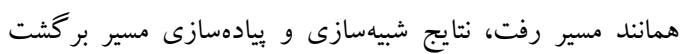
دورزدن تككفرمان ربات شبهخودرو به تر تيب در شكل -ه (الف) و (ب) نشان داده شده است. با توجه به فرمانيذيرى كم ربات شبه خودرو نسبت
جدول r: مشخصات فيزيكى ربات شبهخودرو و خودروى سمند

\begin{tabular}{|c|c|c|c|}
\hline نوع وسيله & ربات اوليه & خودرو & ربات نهايى \\
\hline زاويه فراكثر & $\begin{array}{l}\text { راديان } \\
\text { ران }\end{array}$ & $\begin{array}{l}\text { راديان · • } \\
\text { • • }\end{array}$ & $\begin{array}{l}\text { • • • } \\
\text { راديان }\end{array}$ \\
\hline فاصله & ها & r/9VI & ץ/ • متر \\
\hline عرض & • • • متر & 1/9 متر . & • • • متر \\
\hline طول & Dه • • متر & Y F/D متر & 44/ • متر \\
\hline
\end{tabular}

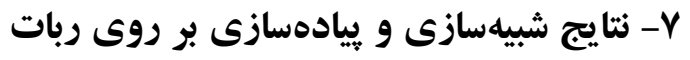

شبه خودرو

در اين بخش به شبيهسازى و بيادهسازى سيستم كنترلى طراحى شده براى دورزدن تكك فرمان خودرو يرداخته مى شود. فرض بر آن است كه

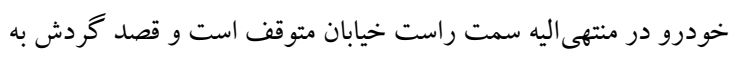
سمت جِّ خيابان را دارد. در ابتدا مسير حركتى رفت و سپس مسير بر گشت دورزدن تككفرمان خودرو مورد بررسى قرار مى گيرد. 
زمانى تعريف شده سبب صفر شدن سرعت ربات در نقاط ابتدايى و انتهايى حر كت شدهاند.

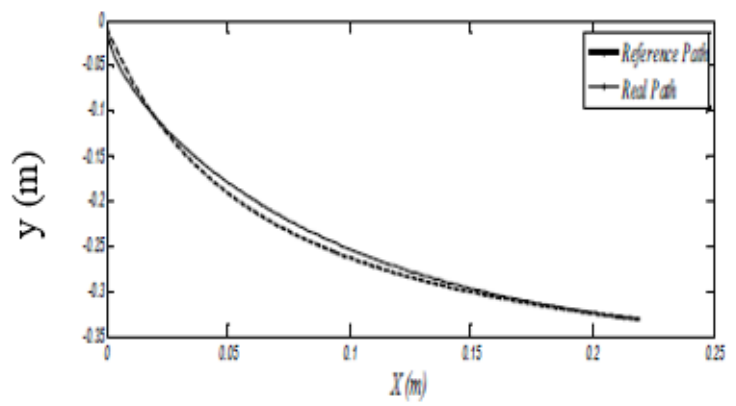

(ب) ييادهسازى مسير مرجع و واقعى ربات

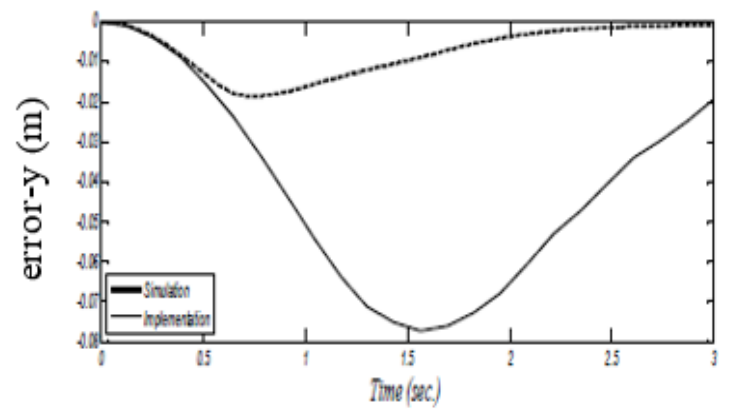

Y- (ت) خطاى حر كتى در راستاى محور )

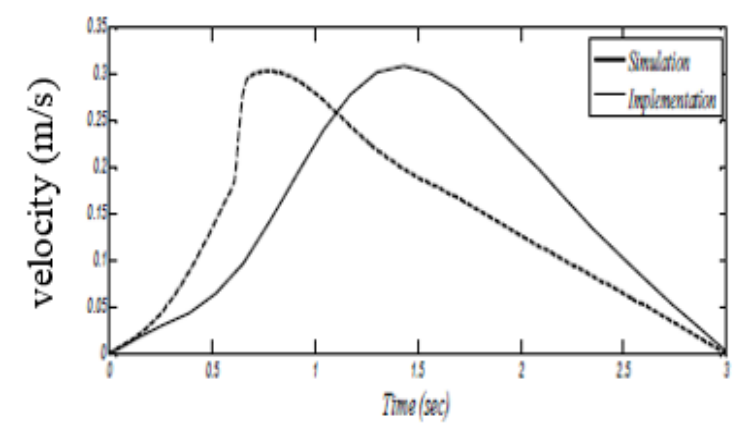

(ج) سرعت فرمان ربات شبه مدرو

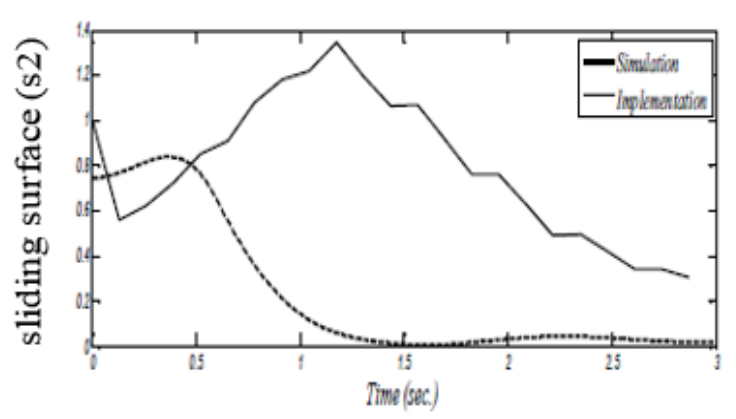

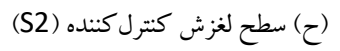

به يكك خودروى واقعى، مقدارى خطا در قسمت پايانى حر كت رخ داده

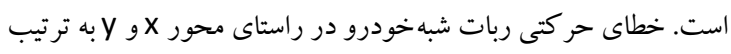

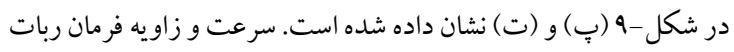
شبه خودرو نيز در شكل-9 (ث) و (ج) نشان داده شده است. مجددا توابع

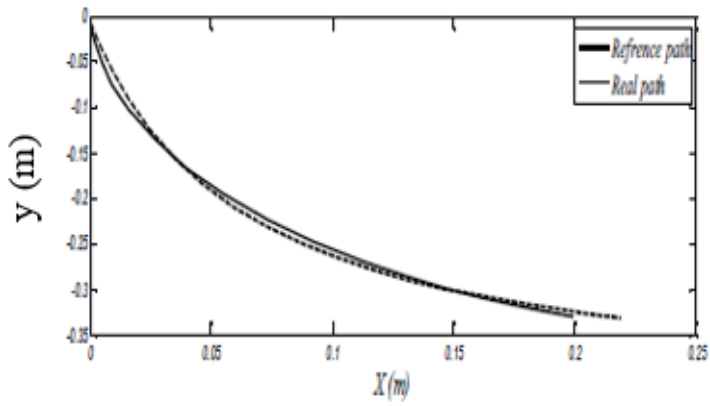

(الف) شبيه سازى مسير مرجع و واقعى ربات

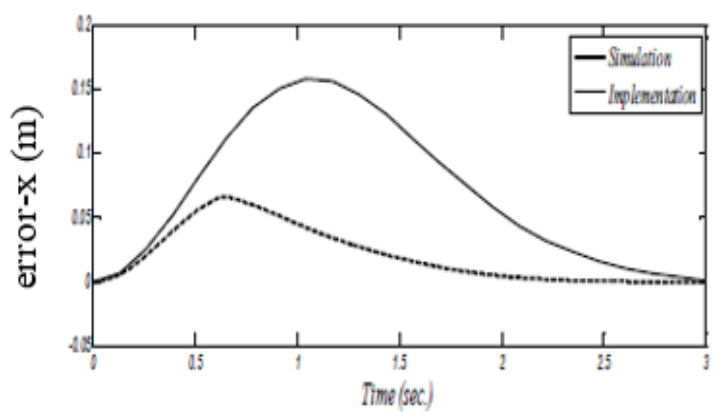

X- (ب) خطاى حر كتى در راستاى محور X

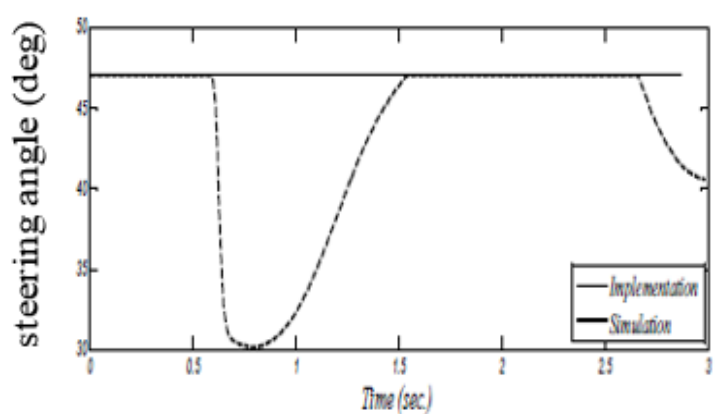

(ث) زاويه هدايت فرمان ربات شبهخودرو

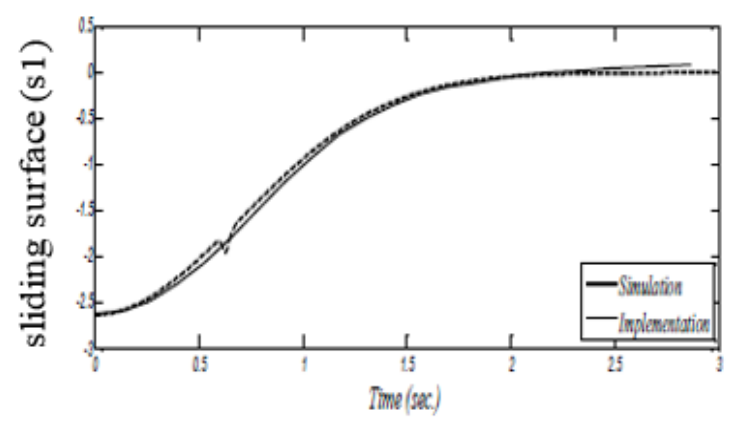

(S1) (ج) سطح لغزش كنترل كننده

شكل-人 شبيه سازى و ييادهسازى مسير رفت دورزدن تككفرمان ربات شبهخودرو 


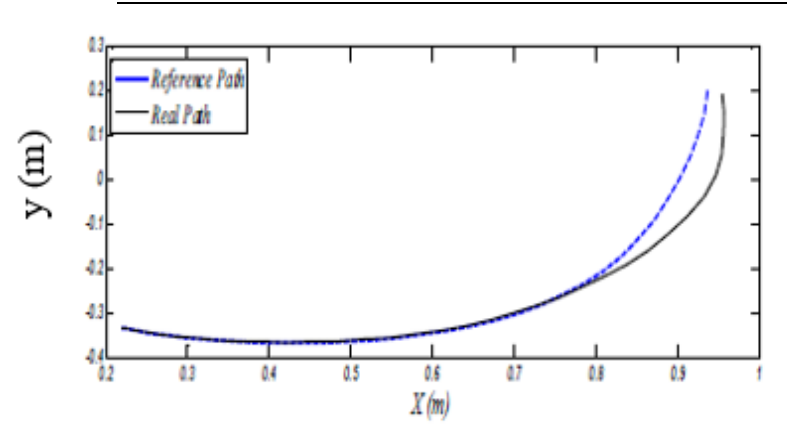

(ب) بيادهسازى مسير مرجع و واقعى ربات

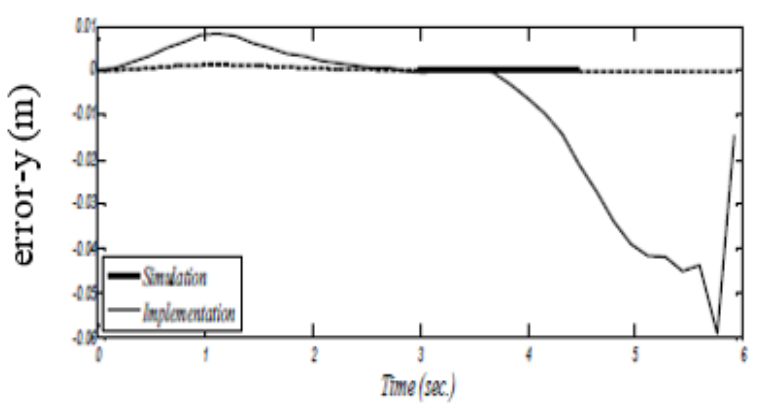

y- خطاى حر كتى در راستاى محور

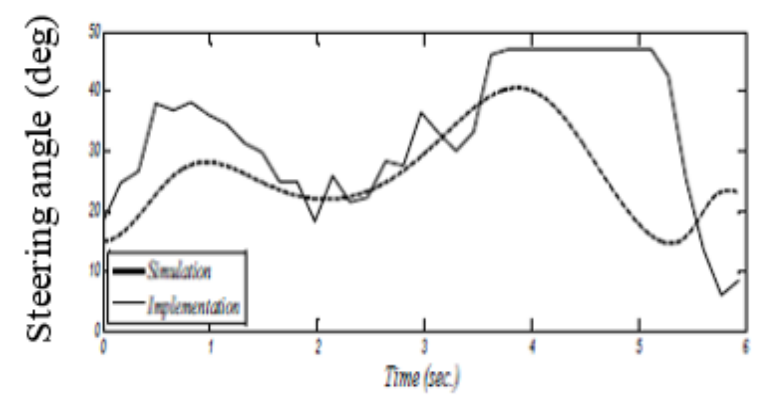

(ج) زاويه هدايت فرمان ربات شبهخودرو

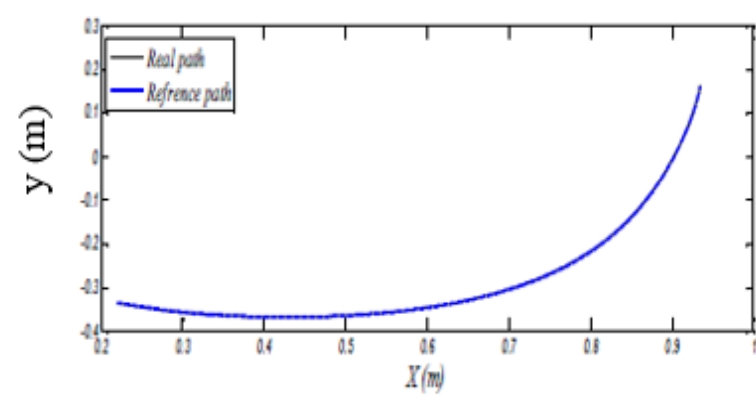

(الف) شبيهسازى مسير مرجع و واقعى ربات

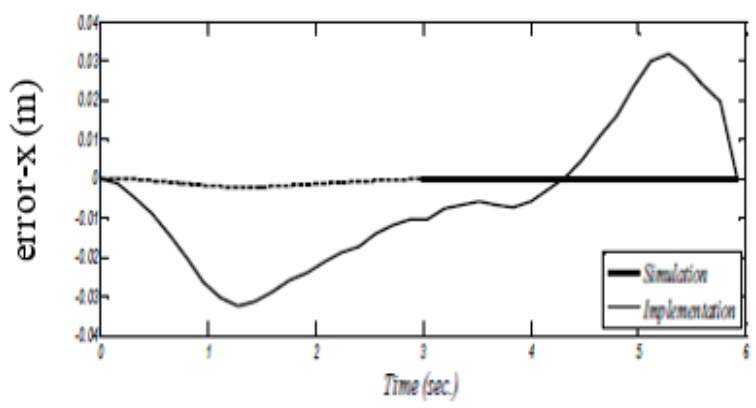

X- X) خطاى حركتى در راستاى محور

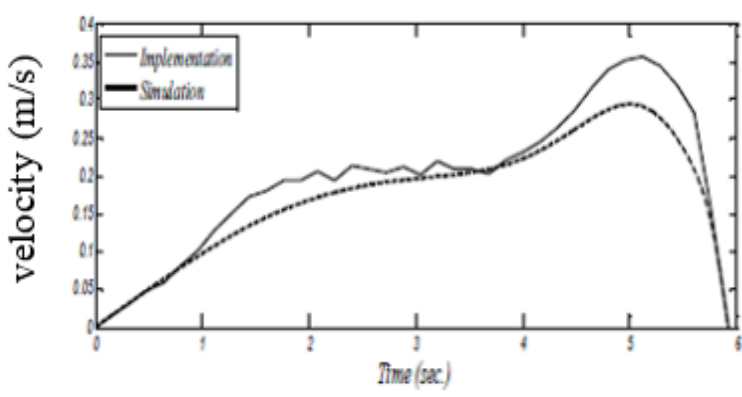

(ث) سرعت ربات شبه خودرو

شكل-9: شبيهسازى و ييادهسازى مسير بر گشت دورزدن تككفرمان ربات شبهخودرو

\section{مراجع}

[1] Fairus, M.A., Najib Sy, S., Jamaludin, I.W. and Kamarudin, M., "Development of an Automatic Parallel Parking System for Nonholonomic Mobile Robot," Electrical, Control and Computer Engineering (INECCE), pp. 45-49, 2011.

[2] Vorobieva, H., Glaser, S., Enache, N. and Mammar, S., "Automatic Parallel Parking with Geometric Continuous-Curvature Path Planning," IEEE Intelligent Vehicles Symposium Proceedings, pp. 465-471, 2014

[3] Guoqiang, Z. and Zhao, L., “A Fuzzy Controller Based on Improved Ant Colony Algorithm for Parallel Automatic Parking," International Journal of Applied Mathematics and Statistics, no. 20, pp. 83-93, 2013.

[4] Dong, H., Jin, Sh. and Hou, Z., "Model Free Adaptive Control for Automatic Car Parking

\section{1- نتيجه كيرى}

در اين بثزوهش به كاربردى جديد در زمينه سيستم حملونقل شهرى

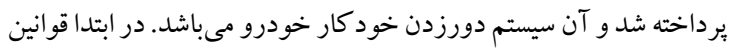

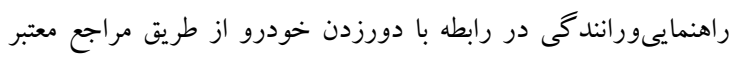

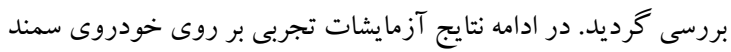

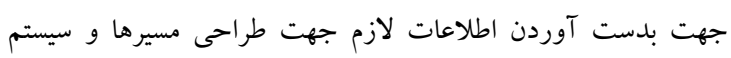

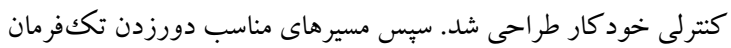

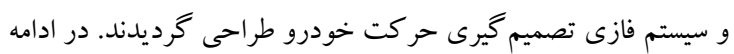
به طراحى سيستم كنترلى مناسب براى تحقق اهداف كنترلى سيستم

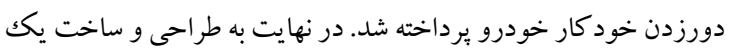

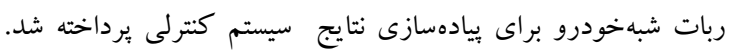

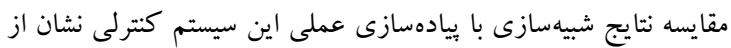
دقت مناسب سيستم كنترلى طر احى شده دارد. 
طراحى و ييادهسازى سيستم كنترل دورزدن خود كار خودرو

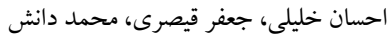

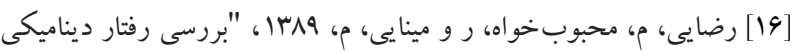

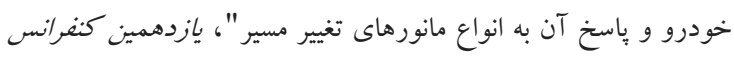

$$
\begin{aligned}
& \text { مهندسى ساخت و توليد /يران. }
\end{aligned}
$$

[5] Naderi Samani, N., Danesh, M. and Ghaisari, J., "Parallel Parking of a Car-Like Mobile Robot Based on the P-Domain Path Tracking Controllers," IET Control Theory \& Applications, vol. 10, no. 5, pp. 564-572, 2016.

[6] Naderi Samani, N., Ghaisari, J. and Danesh, M., "Autonomous Parallel Parking of a Vehicle in a Limited Space Using a RBF Network and a Feedback Linearization Controller," Computer and Knowledge Engineering (ICCKE), pp. 117122, 2012.

[7] Zhang, S., Simkani, M. and Zadeh, M., "Automatic Vehicle Parallel Parking Design Using Fifth Degree Polynomial Path Planning," Vehicular Technology Conference, pp. 1-4, 2011.

[8] Vorobieva, H., Glaser, S., Enache, N. and Mammar, S., "Automatic Parallel Parking in Tiny Spots: Path Planning and Control," IEEE Transactions on Intelligent Transportation Systems, vol. 16, no. 1, pp. 396-410, 2015.

[9] Cheein, A., Carelli, R., Cruz, C. and Bastos-Filho, T., "SLAM-Based Turning Strategy in Restricted Environments for Car-Like Mobile Robots," Industrial Technology (ICIT), pp. 602-607, 2010.

[10] Egerstedt, M. and Stotsky, A., "Control of a CarLike Robot Using a Dynamic Model," IEEE International Conference, vol. 4, pp. 3273-3278, 1998.

[11] Zhang, S.J. and Rachid, A., "Sliding Mode Controller for Automatic Steering of Vehicles," The 27th Annual Conference of the IEEE Industrial Electronics Society, vol. 3, pp. 21492153, 2001.

[12] Azadi, S. and Taherkhani, Z.,"Autonomous Parallel Parking of a Car Based on Parking Space Detection and Fuzzy Controller," International Journal of Automotive Engineering, vol. 2, no. 1, pp. 30-37, 2012.

[13] Pepy, R., Lambert, A. and Mounier, H.,"Path Planning using a Dynamic Vehicle Model," 2nd International Conference on Information \& Communication vol. 1, pp. 781-786, 2006.

[14] Baturone, I., Moreno-Velo, F., Sanchez-solano, S. and Ollero, A., "Automatic design of fuzzy controllers for car-like autonomous robots," IEEE Transactions on Fuzzy Systems, vol. 12, no. 4, pp. 447-465, 2004.

$$
\begin{aligned}
& \text { [10] عيدى، ع، 9^با، "استراتزى كو تاهترين مسير در هدايت يوياى وسيله نقليه }
\end{aligned}
$$

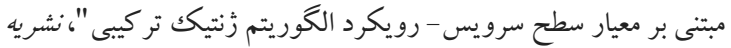

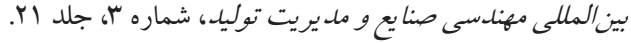

